\title{
Actualidad de Medellín
}

\author{
Gustavo Gutiérrez, \\ Lima, Perú
}

Al cardenal Eduardo Pironio y a Mons. Juan Gerardi, a quienes tanto deben la lglesia y los pobres de América Latina, y a quienes tanto debemos sus amigos.

Hace treinta años se reunió en Medellín la segunda Conferencia General del Episcopado Latinoamericano (CELAM). Nacida del impulso del concilio, estaba llamada a marcar un antes y un después en la vida de la Iglesia de este continente. Personas como don Manuel Lamaín y don Helder Camara, en ese tiempo a la cabeza del CELAM, fueron los primeros en pensar en esla posibilidad. Paulo VI dio una temprana acogida a la idea. Más tarde, oficializada la propuesta, fue preparada cuidadosamente por los obispos latinoamericanos dentro del propósito inicial de hacer presente al Vaticano II en estas tierras de enormes problemas y de grandes esperanzas.

Muchas cosas han pasado en el mundo desde entonces. Ha habido también cambios importantes en la Iglesia. Sin duda, los tiempos de hoy no son los de Medellín. ¿Quiere eslo decir que dicha Conferencia pertenece a un pasado ya superado? Relevante en su momento, ¿habría dejado de serlo ahora? Confrontamos actualmente, se dice, una situación muy diferente, nuevos desafíos, otras exigencias. Medellín resulta extraño a todo eso, se requiere ahora de parte de la Iglesia respueslas inéditas.

Hablar en pretérito de Medellín es lo que intentaron algunos casi al día siguiente de que tuvo lugar. Las razones las conocemos bien y aún subsisten en ciertos círculos. Pero esto no debe ocultamos que en verdad hoy estamos ante mutaciones importantes en la escena latinoamericana y mundial. No cabe duda de que hemos ingresado en una época diferente. La pregunta que surge de inmediato es, por lo tanto, ¿en qué medida y de qué forma afectan los cambios históricos a las profundizaciones doctrinales $\mathrm{y}$ a las líneas pastorales estimuladas por situaciones determinadas? 
En eslas páginas intentaremos hacer algunas anotaciones acerca de la aclualidad de Medellín. Muchos factores intervienen en el asunto. Sabiendo que la lista puede ser más extensa, nos limitaremos a señalar tres de ellos: la ubicación de Medellín en el ciclo conciliar, la lectura de los signos de los tiempos y la persistente interpelación que viene de la pobreza de tantos.

\section{El arco conciliar}

Historiadores y leólogos concuerdan en afirmar que la recepción de los concilios en la lglesia es un proceso que se despliega con cierta lentitud, pero a lo largo de extensos periodosl. Eslo vale de modo particular para el Vaticano II, que asume una perspectiva histórica y retoma los desafíos vividos por la Iglesia en el curso de los úllimos siglos, a la vez que presenta una amplia visión sobre el mundo de hoy y una sólida reflexión teológica, lanzando así el anuncio del evangelio por nuevas pistas. Como se ha dicho muchas veces, la Iglesia y su misión fueron el gran tema del concilio'2. Con seguridad, el aggiornamento de la Iglesia que el concilio debía traer, según los deseos de Juan XXIII, no ha desarrollado todavía todas sus polencialidades.

Medellín fue una pronta y creativa recepción de la asamblea conciliar. Significativamente, la conferencia episcopal fue convocada para estudiar el tema de "La Iglesia en la actual transformación de América Latina a la luz del concilio". Su solo enunciado evoca la preocupación del concilio respecto de la presencia de la Iglesia en el mundo de hoy. La luz conciliar es proyectada sobre todo con la intención de anunciar el reino de Dios en un mundo cambiante. Medellín se plantea el asunto en un ámbito, el de un continente pobre, que no logró - por razones fácilmente explicables- ser tenido en cuenta con toda su gravedad y sus alcan-

1. Ver al respecto el clásico arlículo de Y. Congar "La Réception como réalité cclésiologique", Revue des Sciences Philosophiques ef Theologiques 56 (1972), pp. 369 403. El autor define así la noción de recepción: "el proceso por el cual un cuerpo eclesial hace suya, en verdad, una determinación que no se ha dado a sí mismo, reconociendo que la medida promulgada es una regla que convicne a su vida". La recepción, precisa Congar, más que obediencia, es "un aporte propio de consentimiento, eventualmenle de juicio, en el cual sc cxpresa la vida de un cuerpo que ejerce sus capacidades espirituales" (p. 370). Cfr. Los artículos más recientes de E. Lanne "La notion ecclésiologique de réccplion", Revue Théologique de Louvain 25, 1 (1994), pp. 30-45 y A. Antón "La 'rceepción' en la Iglesia y ecicsiologia”, Gregorianum 77, 1 (1996) pp. 57-96 e idem 77, 3 (1996) pp. 437-469.

2. Pablo VI había reforzado este intcrés conciliar al afirmar, en su encíclica Ecclesiam suam (1964): "pensamos que es deber de la lglesia ahora ahondar en la conciencia que ella licne que tener de si, cn el lesoro de verdad de que es heredera y cuslodia y en la misión que clla debe cjercitar en cl mundo" (n. 19). El concilio fue un gran paso en esta toma de conciencia. 
ces en el concilio. Pero éste señaló las grandes pistas para abordarlo. Entre el Vaticano II y Medellín, Pablo VI publicó su encíclica Populorum progressio (1967). Sus claros términos sobre la situación de los países pobres y las exigencias cristianas consiguientes tuvieron una enorme repercusión en América Latina3. Algunos la consideraron algo así como la Gaudium et spes para el tercer mundo.

Medellín se inscribe claramente en el arco conciliar en el que nos encontramos todavía. Lo ha recordado con firmeza Juan Pablo Il, en su carta Tertio millennio adveniente. El Papa enlaza el concilio con su propuesta de celebración de un jubileo que mira al futuro. "Se puede afirmar - dice- que el concilio Vaticano IJ constituye un acontecimiento providencial, gracias al cual la Iglesia ha iniciado la preparación próxima del jubileo". En seguida, da la razón de esa vigencia: "se trata de un concilio semejante a los anteriores, aunque muy diferente; un concilio centrado en el misterio de Cristo y de su Iglesia, y al mismo tiempo abierto al mundo" (n. 18). De allí que "la enorme riqueza y el tono nuevo, desconocido antes, de la presentación conciliar de estos contenidos constituyen casi un anuncio de tiempos nuevos". Todo lo cual demanda un "renovado compromiso de aplicación, lo más fiel posible de las enseñanzas de Vaticano II a la vida de cada uno y de toda la Iglesia" (n. 20). Son palabras claras que van en la línea de una reafirmación de la actualidad del concilio.

No se puede decir, en efecto, que encontrándonos en una época, en muchos puntos distinta a aquella en la que tuvo lugar el concilio, éste se ha hecho ya obsoleto. Por el contrario, el mensaje de los textos que acabamos de citar es explícito: es necesario enfrentar los retos del presente y del siglo que viene a partir de las líneas evangelizadoras pautadas por el Vaticano II. No se trata de desconocer los cambios operados en nuestro mundo desde entonces. Significa simplemente que el análisis sobre su vigencia debe ser más fino. En asambleas eclesiales como el concilio (y como Medellín), la atención al contexto histórico inmediato es obligada para encontrar las respuestas adecuadas y los caminos apropiados para anunciar el evangelio. Pero esto no puede hacerse, dado el carácter de sus pronunciamientos, sin una profundización del misterio del amor de Dios, del que nos habla la Biblia, y que nunca terminamos de conocer.

Es por ello que Juan XXIII, en sus discursos convocando al concilio, llama simultáneamente a la sensibilidad frente a las cuestiones del momento y a ahondar en el tesoro de la revelación bíblica. No son tareas que puedan ir por cuerdas separadas. Alertados por las interpelaciones históricas, penetramos en las exigencias de la fe para, precisamente, ubicamos como cristianos en el mundo en el

3. Como es sabido, los texlos más citados en Medellín son Goudium et spes y Populorum progressio. 
que vivimos. Se trata, pues, de una relación fecunda, de un verdadero círculo hermenéutico, siempre que no la veamos de un modo mecánico y rígido, ajeno al dinamismo de la historia. Las nuevas miradas de fe, estimuladas por el contomo histórico son, por eso, al mismo tiempo, en buena parte independientes de él, enriquecen en forma definitiva el patrimonio doctrinal de la Iglesia. Evidentemente, varias cosas caducan en ellas conforme pasa el tiempo, pero en la medida en que se acercan a lo substancial del evangelio, tienen la vida larga.

La actualidad del Vaticano II, subrayada por Juan Pablo II, repercute sobre la de Medellín, importante jalón en la ruta seguida por la Iglesia en el tiempo conciliar. Especialmente si tenemos en cuenta que abrió el camino a los encuentros de Puebla y Santo Domingo, que fueron muy insistentes en afirmar su continuidad con Medellín. La recepción del concilio se prolonga así a lo largo de estos años.

\section{Leer continuamente los signos de los tiempos}

Si tomamos las intervenciones de Juan XXIII durante la preparación del Vaticano, podemos notar que todas ellas expresan una inquietud mayor: cómo anunciar el evangelio en el mundo de hoy. La cuestión es seria y preñada de consecuencia. "Tareas de una inmensa gravedad y amplitud —dice el Papaesperan a la Iglesia, como en las épocas más trágicas de su historia"4. Ese es el asunto, ¿cómo hacer para que la Iglesia sea al presente signo visible del reino?s.

El soplo evangelizador nos lleva de la mano a preguntarnos por lo que el Señor quiere decimos a través del devenir histórico de la humanidad. En esa línea, el papa Juan retoma con audacia una idea evangélica de gran alcance: la necesidad de discernir los signos de los tiempos. Debemos hacer nuestra, afirma, "la recomendación de Jesús de saber distinguir 'los signos de los tiempos' (Mateo 16, 4)", estaremos así en condiciones de ver "en medio de espesas tinieblas, no pocos indicios que nos parecen anunciar tiempos mejores para la Iglesia y la humanidad"6. Un auléntico propósilo evangelizador exige una actitud de escucha y de discernimiento de lo que viven las personas. Escrutar los signos de los tiempos es un camino, un mélodo, de acercamiento a esas realidades.

4. "Humanae Salutis" (Constitución apostólica convocando al concilio) en A. y G. Alberigo, Profezia nella fedeltà, Brescia, 1978, p. 345.

5. El cardenal Landázuri, uno de los presidentes de Medellín, plantea esa preocupación al inicio de la conferencia y alude al tema de los signos de los ticmpos: "El pucblo de Dios que vive y sufre en estas tierras quiere decir de sí mismo, por fidelidad al Señor, que desea servir a la humanidad y por ello quiere escnular en los signos de los liempos lo que el Espíritu desea de la Iglesia. Solamente así, el pucblo de Dios será en estas jornadas de la historia, signo alzado entre las naciones" (Discurso inaugural).

6. "Humanae salutis", op. cit., p. 346. 
Como es sabido, el concilio acogió con gran fecundidad la perspectiva sugerida por Juan XXIII. Tenemos diversos y explícitos textos al respecto, pero hay mucho más que eso. Estamos ante un enfoque global que de un modo u otro encontramos en todos los pronunciamientos conciliares?. Es una aproximación a la realidad que se mantiene siempre abierta a los cambios que las siluaciones puedan presentar. Por principio no se aferra a un momento determinado ni a los juicios que él hubiera podido merecer.

Medellín sigue con firmeza e imaginación esta huellaß. Lo afirma desde su Mensaje: "a la luz de la fe que profesamos como creyentes, hemos realizado un esfuerzo para descubrir el plan de Dios en los 'signos de los liempos"”. La razón teológica es indicada de inmedialo: "interpretamos que las aspiraciones y clamores de América Latina son signos que revelan la orientación del plan divino operante en el amor redentor de Cristo que funda estas aspiraciones en la conciencia de una solidaridad fraternal" (n. 3). Y, en efecto, la Conferencia constituyó un inmenso intento por leer, a la luz de la fe y del concilio, en la vida de los pueblos del continente, aquello que el Señor quiere decimos para un oportuno y eficaz anuncio del evangelio.

Por eso mismo, Medellín nos trae una renovada reflexión sobre grandes temas cristianos. La preocupación evangelizadora es siempre motivo de una teología que se alimenta en las fuentes mismas de la revelación biblica. Hemos recordado el papel que los textos conciliares y la Populorum progressio tienen en el espíritu y en los documentos de Medellín, pero la confrontación con la dura realidad del continente hace que ella recorra también senderos inéditos, como, por ejemplo, en el caso de la pobreza y los pobres, que veremos en el párrafo siguiente.

Perfilar una posición propia y percibir los elementos favorables a una vida humana digna y a la presencia del evangelio no era tarea fácil en esos años, contrariamente a lo que a veces se dice y escribe sin preocuparse por buscar una información precisa. La verdad es que la segunda milad de la década de los sesenta no fue de un rácil optimismo en América Latina9. Medellín, sin olvidar

7. No faltaron por cierto las dificultades y reservas en los trabajos conciliares para aceptar esa perspectiva, cfr. M. D. Chenu "Les signes des temps" en Gaudium et spes. L'Eglise dans le monde de ce temps, París, 1967, pp. 95-116.

8. Las dos primeras ponencias presentadas en Medellín fueron consagradas a esta temática: M. McGrath "Los signos de los tiempos en América Latina" y E. Pironio "Interpretación cristiana de los signos de los tiempos hoy en América Latina".

9. Viejas dictaduras en Haití, Paraguay y Nicaragua, gobierno militar en Argentina, un régimen crecientemente duro en Brasil. Violencia guerrillera en Colombia, Venezuela, Perú, Bolivia. En México, 1968 es el año de la matanza de Tlatelolco. Inestabilidad y graves problemas sociales en varios otros paises. 
esa realidad que rechaza en términos fuertes, tiene la perspicacia de ir más lejos y valorar los gérmenes de vida y de liberación que bullían en América Latina.

Puebla y Santo Domingo prosiguen la lectura de los signos de los tiempos. Las referencias son numerosas en sus conclusiones, pero, como en el caso del concilio y de Medellín, se trata sobre todo de un modo de aproximación al contorno histórico, que pone su impronta en el conjunto de sus textos. Es, ya lo hemos dicho, un método siempre abierto al presente. Puebla y Santo Domingo lo asumen con creatividad.

Si encontrarse dentro del arco temporal del concilio le da actualidad a Medellín, ella le viene tambiên de haber iniciado en América Latina una forma de ver la realidad y la presencia de Dios en ella: estar atento a los signos de los tiempos 10. Ya hemos recordado cuáles fueron las fuentes de esas posiciones, pero debe decirse, asimismo, que sin Medellín, el mensaje del Vaticano II y el discemimiento de los signos de los tiempos no habrían entrado en lo cotidiano de la vida de la Iglesia entre nosotros. Numerosos documentos de episcopados nacionales, de reuniones eclesiales, el compromiso de tantos cristianos en estos años prueban la relevancia de esta perspectiva para reorientar continuamente la acción evangelizadora.

\section{El reto de la pobreza}

Los dos factores anotados acerca de la actualidad de Medellín estaban en relación estrecha con el Vaticano II, en cuanto éste se presenta como punto de partida de ellos por lo menos. Quisiéramos añadir ahora un tercero, que tiene más bien sus raíces en el período de la preparación conciliar, pero que se encontró poco presente en el concilio mismo. Nos referimos al reto que la pobreza significa no ś́lo en el campo de lo social, sino como cuestionamiento al corazón de la tarea evangelizadora de la Iglesia y a la propia identidad de ésta.

Discemir los signos de los tiempos lleva a la conferencia de Medellín a mirar cara a cara la realidad de un continente, que vive "bajo el signo trágico del subdesarrollo, que no sólo aparta a nuestros hemanos del goce de los bienes materiales, sino de su misma realización humana", se dice ya en el Mensaje. Subdesarrollo que "es una injusta situación promotora de tensiones que conspiran contra la paz" ( $P a z$ 1). Esa situación será llamada también "una dolorosa pobreza cercana en muchísimos casos a la inhumana miseria" (Pobreza de la lglesia 1). "Miseria, como hecho colectivo [que] es una injusticia que clama al cielo" (Justicia 1). Injusticia que a su vez expresa "una situación de pecado" (Paz 1).

10. Puebla toma nota de esto y señala que "sobre todo a partir de Medellín, con clara conciencia de ser misión abierta lealmente al diálogo, la Iglesia escruta los signos de los tiempos" (n. 15). 
Los textos que acabamos de citar se hallan al comienzo de esos documentos y dan el tono de los desarrollos que encontraremos más tarde en ello.

Medellín considera que esa situación de pobreza es el mayor desafío al cual debe hacer frente el anuncio del evangelio en estas tierras. Proclamación de un reino de amor y paz incompatible con la "violencia instilucionalizada", en que viven los pobres de América Latina (Paz 16) II. No es posible, por consiguiente, ser "indiferente ante las tremendas injusticias sociales existentes en América Latina" (Pobreza 1). La conferencia llama a los cristianos a comprometerse en la construcción de una sociedad justa, sin marginados ni oprimidos. De éstos brota hoy un "sordo clamor" por "una liberación que no les llega de ninguna parte" (Pobreza 2). Grito al que Medellín (y más tarde Puebla n. 88) quiere responder.

Por liberación Medellín entiende, siguiendo la reflexión teológica latinoamericana de esos días, "una liberación plena", en la que se ofrezcan "las riquezas de una salvación integral en Cristo el Señor" (Catequesis 6) 12. Por ello, una "verdadera liberación" exige de todos "una profunda conversión a fin de que llegue a nosotros el reino de justicia, de amor y de paz" (Justicia 3) 13. En vistas a la liberación total, Medellín propone "que se presente cada vez más nítido en América Latina el rostro de una Iglesia auténlicamente pobre, misionera y pascual, desligada de todo poder temporal y audazmente comprometida en la liberación de todo el hombre y todos los hombres" (Juventud 15)14.

11. La expresión "violencia institucionalizada" sorprendió mucho entonces y no faltaron quienes la consideraron ajena a las categorías cientílicas de análisis de la sociedad. No obstante, al año siguiente, 1969, J. Galtung, uno de los mayores especialistas actuales en matcria de paz y violencia, acuñó la noción de "violencia csiructural". Basta leer sus textos para comprobar la cercanía de sus ideas con las presentadas en Medellín (cfr. J. Galtung "Violence, Pcace and Peace Research", Journal of Peace. Research VI, 1969, 3).

12. Tiene razón la conferencia de Puebla cuando afirma: "en Mcdellín se despliega un proceso dinámico de liberación integral cuyos ecos positivos recoge la Evangelii nuntiandi y el Papa Juan Pablo II en su Mensajc a esta conferencia" (n. 480).

13. Este último texlo viene inmediatamente después de uno de los pasajes más netos sobre el carácter integral de la liberación: "es el mismo Dios quien, en la plenitud de los tiempos envia a su Hijo para que hecho carne, venga a liberar a todos los hombres de todas las esclavitudes a que los tiene sujetos el pecado, la ignorancia, el hambre, la miseria y la opresión, en una palabra, la injusticia y el odio que tienen su origen en el egoísmo humano" (ibid.).

14. Se trata de un texto que el cardenal E. Pironio tenía en gran aprecio y que citaba siempre. 
El documento Pobreza de la Iglesia da importantes precisiones acerca del testimonio de pobreza. Para el efecto, y recogiendo una pista que se abria paso en esos días en América Latina, nos entrega una interesante reflexión sobre el sentido bíblico de la pobreza. Las distinciones que establece ayudan a poner orden y claridad en un tema complejo, y por momenos confuso. Ellas constituyeron un punto de partida para profundizaciones ulteriores.

Lo que importa es la trabazón entre las diferentes nociones presentadas. La primera de ellas, la pobreza material, como carencia de los bienes de este mundo, lejos de toda idealización, es considerada como un mal en ella misma. La pobreza espiritual significa, en primer lugar, una actitud de infancia espiritual, de disponibilidad a la voluntad de Dios; una consecuencia de ella será el desprendimiento interior frente a los bienes temporales 15 . Esta manera de ver lleva necesariamente a preguntamos por qué razón debe asumirse un género de vida pobre. Medellín responde diciendo que la pobreza, en cuanto compromiso voluntario de los cristianos, debe expresar simultáneamente la solidaridad con los pobres y el rechazo de la pobreza material, en cuanlo que es algo no querido por Dios. El fundamento cristológico de este enfoque es señalado explícitamente (cfr. Pobreza 4)16.

Partiendo de estas precisiones, el testimonio de una Iglesia pobre es visto como una denuncia de la pobreza y de sus causas, y también como un compromiso por recorrer, como se dice en el concilio, "el sendero de la pobreza" (Ad gentes 5). De este modo, la Iglesia estará en condiciones de "predicar y vivir la pobreza espiritual, como actitud de infancia espiritual y apertura al Señor" (Pobreza 5). La infancia espiritual significa reconocer a Dios como amor, es lo que el Padre quiere decir, y como consecuencia, reconocer a los demás, en tanto hermanas y hermanos. Estamos, pues, en el núcleo del mensaje evangélico.

Es oportuno subrayar que para Medellín, si bien la pobreza tiene aspectos sociales y económicos fundamentales, las cosas no quedan ahí. Es una situación humana global. Los pobres son los "insignificantes", aquellos que por razones económicas, raciales, culturales o por ser mujeres tienen poco o ningún peso en la sociedad y ven sus derechos violados y su realización humana impedida. La condición de los pobres constituye por ello una auténtica interpelación a la misión de la Iglesia. Esta debe acoger el llamado a redefinir su larea ante la magnitud de una situación contraria a la voluntad de Dios.

15. Un persistente error (de origen dactilográfico seguramente) en la edición del documento de Pobreza coloca la nota 4 al final del párrafo sobre la pobreza espiritual, cuando en realidad corresponde — como estaba en el original - al término del párrafo acerca de la pobreza como un mal.

16. A partir de ese lundamento "la preferencia efecliva [por] los sectores más pobres y necesitados y a los segregados por cualquier causa" (Pobreza 9) es encuadrada en el amor universal de Dios del que nadie eslá fuera ( $c f r . / d .8$ y 18). 
Eslo fue lo que Juan XXIII planteó al concilio, cuando le sugirió el tema de "la Iglesia de todos y particularmente la Iglesia de los pobres" (Discurso del II de septiembre de 1962). Por diversas razones, y pese a los esfuerzos del cardenal Lercaro y de otros padres conciliares, el asunto no llegó a tener en el Vaticano II la presencia que el Papa hubiese deseado17. Le cupo a Medeliín tomar la posta y comenzar a perfilar la tarea de la Iglesia frente a los desafíos que lanza la pobreza, no sólo, reiteramos, a su inquietud social, sino al anuncio del evangelio, tomado como un todo.

Puebla y Santo Domingo prolongan las intuiciones de Medellín y profundizan creativamente la perspectiva iniciada en esa conferencia18. Puebla recoge de Medellín y de la experiencia y reflexión de los años posteriores a esta asamblea la expresión opción preferencial por el pobre. Ella no se comprende, por esa razón, sin referencia a las distinciones sobre la noción de pobreza que recordábamos líneas arriba. Justamente, las tres palabras de la frase mencionada (pobre, preferencia, opción) remiten a los tres conceptos ditinguidos en Medellín (pobreza malerial, pobreza espiritual, pobreza como compromiso) ${ }^{19}$. Hoy, como es bien conocido, la perspectiva (y la letra) de la opción preferencial por el pobre pertenece al magisterio universal de la Iglesia. Juan Pablo lo ha reiterado en numerosas ocasiones 20 .

Un punto capital del enfoque de la pobreza en Medellín es no haberse limitado a describirla. Hay una preocupación por señalar las causas que la provocan. Esta fue una de las grandes novedades y aportes de esta conferencia. Lo reconoce con franqueza el sínodo convocado para celebrar el vigésimo aniversario de la clausura del concilio (1985): “Después del Concilio Vaticano II, la Iglesia se ha hecho más consciente de su misión para el servicio de los pobres, los oprimidos y los marginados" (D. 6, subrayado nuestro). El "después del concilio" es exacto, es un reconocimiento de la novedad mencionada y remite con certeza a las vivencias y reflexiones de la lglesia de América Latina y el Caribe, que se expresan en buena parte en Medellín y Puebla. El interés por conocer y denunciar lo que motiva la pobreza no es un refinamiento intelectual, es una manifestación de lealtad con los pobres. Si no vamos hasta las raíces del asunto será

17. Lumen gentiun 8 y Ad gentes 5 son, sin embargo, textos interesantes al respecto.

18. Por ejemplo, con la invitación a ver los rasgos de Crísio en los variados rostros de los pobres (nn. 31-39). Texto que se debe a las manos de dos grandes obispos Leonidas Proaño de Riobamba y Germán Schmitz, auxiliar de Lima (cfr. También Santo Domingo 179).

19. Cfr. G. Gutiérrez "La opción preferencial por los pobres", La religión en los albores del siglo XXI (Bilbao, Universidad de Deusto, 1994), pp. 107-121.

20. Ella se encuentra también en textos de episcopados nacionales de Nortcamćrica, Asia y otros lugares. 
imposible enfrentar debidamente la condición que ellos padecen. Puebla y Santo Domingo han adoptado la misma perspectiva. Actitud fortalecida por los frecuentes textos de Juan Pablo II que denuncian con nitidez los mecanismos sociales y económicos, que dan lugar a la pobreza2t.

Estamos, por consiguiente, ante una vigorosa postura frente a la pobreza que ha recordado a la Iglesia toda el papel que tienen los últimos de la historia, los "insignificantes" de ella, en el designio salvador de Dios. Desgraciadamente, la condición de los pobres, lejos de haber mejorado, se ha hecho aún más grave. Además, la brecha entre pobres y ricos (naciones y personas) es mayor que en la época de Medellín. Todos los informes internacionales lo prueban a saciedad. El reto de la pobreza y la marginación sigue presente, no debe extrañar por eso que las conferencias de Puebla y Santo Domingo asuman francamente el giro dado en Medellín. Ellas recuerdan otros retos que se presentan a la función evangelizadora de la lglesia22, pero, venciendo no pocas oposiciones, reafirman el carácter vertebrador de la opción por los pobres. Tienen en cuenta su compleja situación, con sus vertientes económicas, culturales, raciales, de género, y presentan una contribución capital a la reflexión sobre esta opción, así como sobre las líneas pastorales que se derivan de ella.

- Por estas y otras razones, a treinta años de distancia, la conferencia episcopal de Medellín sigue siendo un punto de referencia obligado. Al decir esto no negamos que, en ciertos aspectos, sus textos representan una respuesta a tiempos que no son los de hoy. Pero lo substancial de su mensaje permanece. Como ya lo hemos dicho, su pertenencia al arco conciliar, al impulso que viene del Vaticano II, la flexibilidad y la fidelidad a los nuevos desafíos de la lectura de los signos de los tiempos, y la interpelación que viene de una pobreza que se acrecienta hacen ver su vigencia en nuestro días23.

- Uno de los significados más importantes y duraderos de Medellín es el hecho de que en esa conferencia, la Iglesia latinoamericana expresa su madurez.

21. El último texto al respecto se encuentra en uno de los discursos durante su visita a Cuba. Después de recusar "una forma de neoliberalismo capitalista que subordina la persona humana y condiciona el desarrollo de los pueblos a las fuerzas ciegas del mercado", el Papa sostienc "se asiste en el concierto de las naciones al enriquecimiento exagerado de unos pocos a costa del empobrecimiento creciente de muchos, de forma que los ricos son cada vez más ricos y los pobres cada vez más pobres" (Homilla del 25 de enero de 1998).

22. La secularización, por ejemplo, presente en algunos ambientes de América Latina y el Caribe, también mencionada en Medellín: Juventud 4, Catequesis 2.

23. Sin duda, la fecunda propuesta del jubileo, hecha por Juan Pablo ll, dará un nuevo soplo a los temas caros a Medellín, que son precisamente los que nos presentan las raíces biblicas de aquél. 
Ser una Iglesia adulta que confronte sin tapujos la realidad histórica en la que vive es la condición de una auténtica comunión con la Iglesia universal. El cardenal Landázuri recogió la clara y emocionada percepción que de esto se tenía en Medellín, en su discurso de clausura de la conferencia, siguiendo la pauta dada por Pablo VI, en el texto que hemos citado antes de la Ecclesiam suam. Buscando responder a la pregunta ¿quiénes somos?, decía: "somos hombres de un pueblo que comienza a descubrir en la encrucijada de las naciones, su propia conciencia, su propio quehacer". Y añadía: "somos pastores en este pueblo de Dios que, como testigos del Maestro en todo el mundo, vamos a descubrir nuevos rumbos del Señor" 24.

* La búsqueda de esos "nuevos rumbos" no ha sido un camino fácil pero su fecundidad evangélica no ofrece dudas. Entre otras cosas porque en ese andar muchos han visto segadas violentamente sus vidas. Mons. Juan Gerardi es el último en una larga y dolorosa lista. Personas y amigos cercanos como él alimentan nuestra fe y nuestra esperanza. $Y$ ayudan a comprender en qué consiste finalmente la actualidad de Medellín.

24. En otro pasaje declaraba: "Hay algo muy característico en los planteamientos que nos hemos hecho durante estos días y que deseo subrayar. Es esto: nosotros enfrentamos nuestros problemas. Hay una servidumbre que no es comunión. Hay una dependencia psicológica y sociológica, que no responde a la intima trabazón del cuerpo del Señor. Encarar nuestros problemas exige madurez. Es una forma privilegiada de expresar la colegialidad episcopal y la comunión con toda la Iglesia". Agregaba por eso: "intentamos buscar soluciones desde dentro de nuestras realidades y posibilidades; ello va a permitir a la Iglesia universal, como en otras elapas históricas, enriquecerse con nuevas formas eclesiales y pastorales". 